\title{
A radioisotope method of measuring intragastric volumes using the Volémetron
}

\author{
R. A. HINDER AND C. G. BREMNER \\ From the Department of Surgery, University of the Witwatersrand, and Johannesburg Hospital, \\ Johannesburg, South Africa
}

SUMMARY A new method of measuring intragastric volumes using the Volémetron and ${ }^{125}$ RIHSA is reported. The method has been used to measure serially the change in intragastric volumes following milk and water feeds in a group of six dogs.

Various methods of measuring gastric emptying have been employed over the years (Hunt and Spurrell, 1951; George, 1968; Cavell, 1969; Horton, Ross, and Darling, 1965; Griffith, Owen, Kirkman, and Shields, 1966; Chernish, Young, Rosenak, and Redman, 1967), but each one of the methods can be shown to have some disadvantage or cause for inaccuracy.

The method used by us involves the adaptation of the Volémetron for the measurement of intragastric volumes. The Volémetron is an apparatus normally used for the measurement of blood volume: a quantity of ${ }^{125}$ RIHSA of known radioactivity is injected intravenously. The radioactivity of samples of blood is measured before and after the addition of the ${ }^{125}$ RIHSA. The dilution factor indicates the volume of fluid to which the ${ }^{125}$ RIHSA was added. The result is automatically calculated by the machine. Similarly the Volémetron can be used to calculate the volume of gastric content.

\section{Method}

Mongrel dogs of both sexes weighing approximately 15 kilograms were used. They were trained to accept a $1 \mathrm{~cm}$ double lumen rubber or Salem ${ }^{1}$ orogastric tube, using a mouth gag. No sedation was used. When the dog accepted the tube without any agitation he was used for testing. All dogs were allowed only water for 24 hours before testing. Long-haired dogs were avoided, as swallowed hair in the stomach may block the tube and hamper aspiration.

The pattern of gastric emptying of either milk or water was tested. Only one test per day was carried

'Sheridan Corporation (New York).

Received for publication 20 November 1972. out on any particular dog. A milk feed was made up by diluting $110 \mathrm{ml}$ of Carnation milk in $190 \mathrm{ml}$ of water.

The tube was passed and the stomach washed out with $200 \mathrm{ml}$ of normal saline. If food was present in the return, or if the return was below $160 \mathrm{ml}$ the test was discontinued. This occurred infrequently. A volume of $20 \mathrm{ml}$ per kilogram body weight of water or reconstituted Carnation milk was passed into the stomach, and the tube and gag were removed. The dogs were kept free of restraint and on all fours at all times. Ten minutes later the tube was again passed into the stomach via the gag. The stomach contents were mixed well by repeated to and fro aspiration with a bulb syringe. A $2 \mathrm{ml}$ 'premix' sample of the mixed stomach contents was taken and kept for measurement in the Volémetron. Then $0.35 \mathrm{ml}$ of ${ }^{125}$ RIHSA, the radioactivity of which had been measured by the Volémetron, was injected, via the fine bore lumen of the tube, into the stomach. This was washed through with $10 \mathrm{ml}$ of meal fluid. Following adequate mixing, a $12 \mathrm{ml}$ 'postmix' sample of gastric contents was taken. Ten $\mathrm{ml}$ of the 'postmix' sample was kept to wash through the dose of ${ }^{125}$ RIHSA for the following test 20 minutes later, and the remaining $2 \mathrm{ml}$ kept for measurement in the Volémetron. The tube and gag were again removed. The syringe used to inject the ${ }^{125}$ RIHSA had its residual radioactivity measured by the Volémetron. The radioactivity of the 'premix' and 'postmix' specimens was measured in the Volémetron, and the gastric volume automatically computed and displayed; $10 \mathrm{ml}$ was subtracted from this reading to allow for the volume of fluid added to wash through the ${ }^{125}$ RIHSA at each measurement.

The gastric volume was measured every 20 minutes by this method, until the volume approached 
$50 \mathrm{ml}$. The stomach content was then completely aspirated and the volume measured in a measuring flask as a check.

\section{Results}

A typical example of the log of the intragastric volume plotted against time for two tests each of milk and water on a particular dog is shown in the figure.

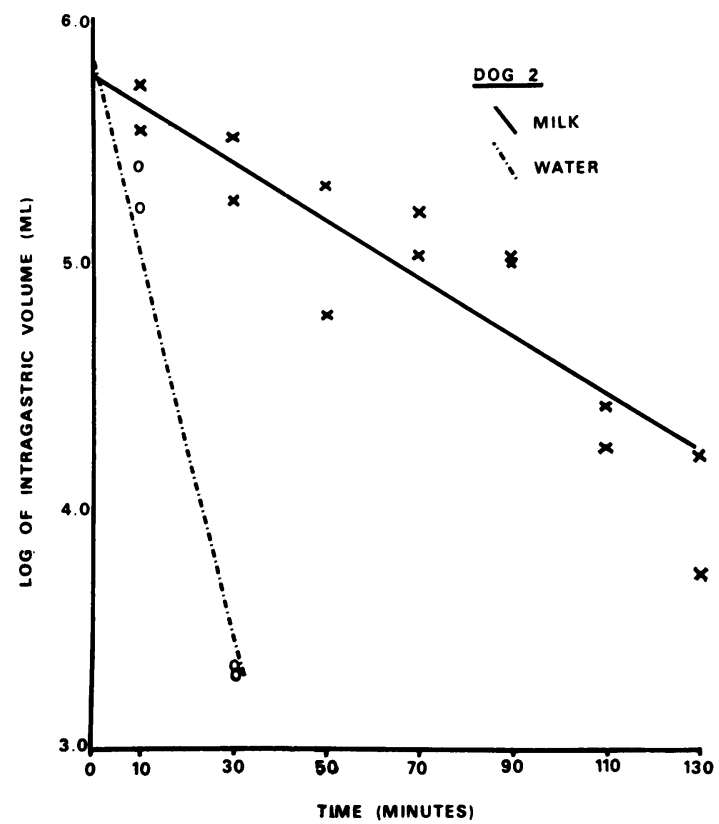

Fig. Change of intragastric volume with the computed regression lines following two milk and two water feeds.

The regression constants of log volume of meal remaining on time with the standard errors of the slopes for the six dogs is shown in Table I.

Water was shown to empty appreciably faster than

\begin{tabular}{lll}
\hline Dog No. & Water & Milk \\
\hline 1 & $-0.0330( \pm 0.0023)$ & $-0.0090( \pm 0.0001)$ \\
2 & $-0.0808( \pm 0.0000)$ & $-0.0121( \pm 0.0021)$ \\
3 & $-0.0382( \pm 0.0071)$ & $-0.0118( \pm 0.0221)$ \\
4 & $-0.0495( \pm 0.0021)$ & $-0.0102( \pm 0.0017)$ \\
5 & $-0.0516( \pm 0.0246)$ & $-0.0196( \pm 0.0002)$ \\
6 & $-0.0864( \pm 0.0003)$ & $-0.0225( \pm 0.0038)$
\end{tabular}

Table I Regression constants of log volume of meal remaining on time, of milk and water, with standard errors for two tests milk. This confirms previous work (Ludwick, Wiley, and Bass, 1970; McKelvey, 1970).

Bile was found to be present only in the last one or two specimens.

The measured residual volume was often slightly less than that calculated. This is probably due to the inability to aspirate the stomach contents totally.

\section{Assessment of Accuracy of Method}

The accuracy of the method has been checked with a water meal on two dogs using the double sampling method of George (1968) (phenol red). Good correlation of results was obtained (Table II).

\begin{tabular}{lll}
\hline Dog & Phenol Red Method & Isotope Method \\
\hline A & $-0.0361( \pm 0.0026)$ & $-0.0266( \pm 0.0121)$ \\
B & $-0.0332( \pm 0.0167)$ & $-0.0273( \pm 0.0012)$ \\
\hline
\end{tabular}

Table II Regression constants of log volume of meal remaining on time, with standard errors for two tests, using the phenol red and isotope methods

We also assessed whether ${ }^{125}$ RIHSA could be absorbed from the gastric mucosa. Three $\mathrm{ml}$ of ${ }^{125}$ RIHSA in $200 \mathrm{ml}$ milk was injected into a dog Heidenhain pouch. Over one hour there was no appreciable change in ${ }^{125}$ RIHSA concentration in the pouch. This absorption test was also studied in the intact pyloric ligated stomach in a dog under anaesthesia. There was again no evidence of loss of ${ }^{125}$ RIHSA from the stomach. To exclude the possibility of error due to absorption of ${ }^{125}$ RIHSA from the small bowel, and subsequent secretion into the stomach, the test was repeated with $3 \mathrm{ml}$ of ${ }^{125}$ RIHSA in the jejunum of the pyloric ligated dog. There was no evidence of increased concentration of ${ }^{125}$ RIHSA in the stomach over one hour. This would confirm the findings of Bloom, Jacobson, and Grossman (1967) and Davenport (1943).

A cross check in vitro of the accuracy of the method has shown only a $5 \%$ range of error.

\section{Discussion}

The method has the advantage of being quick, accurate, and easy to perform. The tedious filtrations and calculations of some other methods are avoided. A complete curve of emptying can be obtained at one session. However, the disadvantage is that only a fluid meal may be used.

Reconstituted Carnation milk is a fluid meal which conforms very closely to a British diet (Table III) (McKelvey, 1970). It can therefore be regarded as a 


\begin{tabular}{lc}
\hline Butter fat & $2.9 \%$ \\
Carbohydrate & $3 \cdot 6 \%$ \\
Protein & $2 \cdot 5 \%$ \\
Minerals & $0 \cdot 5 \%$ \\
Water & $90 \cdot 5 \%$ \\
Osmolality & 670 mosmoles per kg \\
pH & $6 \cdot 3$ \\
\hline
\end{tabular}

Table III Composition of reconstituted Carnation milk

good balanced meal containing carbohydrate, protein, and fat.

The repeated passage of the orogastric tube is not thought to have any disadvantages over the cervical canula provided the experimental animal is trained. Hunt found no difference in gastric secretion or emptying between swallowed and instilled meals (Hunt and MacDonald, 1951).

We wish to thank Professor du Plessis for his criticism and facilities given in his Department and Mr P. R. Tuffin for statistical aid. All experiments were performed in the Michael and Janie Miller Experimental Laboratory.
This work was supported by MRC grant no. M14/71/S1.

References

Bloom, D. S., Jacobson, E. D., and Grossman, M. I. (1967). Validation of dilution indicators in the stomach. Gastroenterology, 52, 205-210.

Cavell, B. (1969). Gastric emptying in infants. Lancet, 2, 904-905.

Chernish, S. M., Young, E. B., Rosenak, B. D., and Redman, C. E. (1967). A comparison of two methods of measurement of gastric emptying time. Amer. J. dig. Dis., 12, 761-774.

Davenport, H. W. (1943). The secretion of iodide by the gastric mucosa. Gastroenterology, 1, 1055-1061.

George, J. D. (1968). New clinical method for measuring the rate of gastric emptying: the double sampling test meal. Gut, 9, 237-242.

Griffith, G. H., Owen, G. M., Kirkman, S., and Shields, R. (1966). Measurement of rate of gastric emptying using chromium-51. Lancet, 1, 1244-1245.

Horton, R. E., Ross, F. G. M., and Darling, G. H. (1965). Determination of the emptying-time of the stomach by use of entericcoated barium granules. Brit. med. J., 1, 1537-1539.

Hunt, J. N., and MacDonald, I. (1951). The effect of intra-gastric instillation of a meal on gastric function in man. J. Physiol. (Lond.), 113, 185-188.

Hunt, J. N., and Spurrell, W. R. (1951). The pattern of emptying of the human stomach. J. Physiol. (Lond.), 113, 157-168.

Ludwick, J. R., Wiley, J. N., and Bass, P. (1970). Gastric emptying following Finney pyloroplasty and vagotomy. Amer.J. dig. Dis., 15, 347-352.

McKelvey, S. T. D. (1970). Gastric incontinence and post vagotomy diarrhoea. Brit. J. Surg., 57, 741-747. 